\title{
A sala de aula invertida e a problematização aplicadas ao ensino da Física Il: um estudo de caso no curso de graduação em engenharia civil do UniFOA no período letivo de 2017.1
}

\author{
Fipped classroom and problematization applied to the teaching of \\ Physics II: a case study of civil engineering in UniFOA in 2017.1
}

1 Izabel de Oliveira da Mota izabel.mota@foa.org.br

1 Centro Universitário de Volta Redonda e Universidade Federal Fluminense

\section{Resumo}

O objetivo deste estudo de caso foi avaliar o uso das metodologias de aula invertida e problematização como estratégias de ensino-aprendizagem para o conteúdo de óptica, parte integrante da disciplina de Física II da grade curricular do curso de graduação em Engenharia Civil do UniFOA. O material didático para estudo individual foi disponibilizado on-line por meio da área restrita virtual dos estudantes e os alunos tiveram 2 semanas para realizar essa etapa da atividade. Houve dois momentos de testes individuais de conhecimento, um pré-estudo e outro pós-estudo. Houve discussão presencial do assunto em grupos de trabalho (GT) para elaboração de gabarito único por GT. Também foi realizada uma mesa redonda com todos os GTs. Após essa etapa, foi proposta uma atividade de problematização do tema, na qual os alunos em seus respectivos GTs produziram um vídeo de 20 minutos sobre assuntos relacionados às importâncias e aplicações da óptica na engenharia para resolução de problemas. Os resultados da avaliação demonstram que houve significativa aquisição de competências após a aplicação das metodologias ativas. Após o ciclo de atividades, $84 \%$ dos estudantes afirmaram que atividades como essa ampliam a sua aprendizagem. Além disso, $81 \%$ dos alunos declararam que se sentem motivados e $78 \%$ afirmaram que se sentem autônomos no processo de aprendizagem após a experiência.

\section{Palavras-chave}

Metodologias ativas. Aprendizagem. Tecnologias de informação. Ensino.

\begin{abstract}
The purpose of this case study was to evaluate the use of flipped classroom methodologies and problem-solving as teaching-learning strategies for optics content, an integral part of the discipline of Physics II of the curriculum of the graduate course in Civil Engineering in UniFOA. The didactic material for individual study was made to be available online through the virtual restricted area of the students, who had 2 weeks to perform this stage of the activity. There were two moments of individual knowledge tests, one previous study and one post study. There was a faceto-face discussion of the subject in working groups for their preparation of a single template. A round table with all groups was also held. After that stage, an activity of problematization of the theme was proposed, in which the students in their respective working groups produced a video of 20 minutes on subjects related to the importance and applications of optics in engineering for problem solving. The results of the evaluation show there was a significant acquisition of skills after the application of the active methodologies. After the cycle of activities, $84 \%$ of the students stated that such activities increase their learning. In addition, $81 \%$ of students stated that they felt motivated and $78 \%$ stated that they feel autonomous in the learning process after the experience.
\end{abstract}

\section{Keywords}

Active methodologies. Learning. Information technologies. Teaching.

\section{Como você deve citar?}

MOTA, Izabel de Oliveira da. A sala de aula invertida e a problematização aplicadas ao ensino da física II: um estudo de caso no curso de graduação em engenharia civil do UniFOA no período letivo de 2017.1.Cadernos UniFOA, Volta Redonda, n. 42, p. 07-12, abril, 2020. 
A sala de aula invertida e a problematização aplicadas ao ensino da física II: um estudo de caso no curso de graduação em engenharia civil do UniFOA no período letivo de 2017.1

\section{INTRODUÇÃO}

A evolução das tecnologias da informação e comunicação (TICs) revela um novo panorama educacional, no qual o acesso à informação é cada vez mais aberto e inclusivo e os modelos tradicionais de ensino não mais atendem aos objetivos da sociedade contemporânea (ARAÚJO, 2011).

Esse cenário exige que os profissionais da educação busquem por práticas pedagógicas mais inovadoras e capazes de oportunizar uma formação mais autônoma, crítica e com o desenvolvimento de novas habilidades na perspectiva de acompanhar o atual contexto, a partir de problemas reais, pautadas no conhecimento inter, multi e transdisciplinar (CUNHA, 2006; HENGEMÜHLE, 2008).

Valente (2014) afirma que muitas estratégias têm sido usadas para promover uma aprendizagem ativa e essas alternativas pedagógicas devem transferir o foco do processo de aprendizagem para o aprendiz.

Schmitz e Reis (2018) consideram a metodologia de Sala de Aula Invertida (SAI) ou Flipped Classroom $(F C)$ como uma estratégia que pode potencializar novas abordagens na prática de ensino, especialmente no ensino superior, já que tem suas origens no ensino híbrido (blended learning), ou seja, as instruções são recebidas on-line, antes de o aluno frequentar a aula, transformando a sala de aula em um ambiente para discussões em grupo e resolução de problemas, e o papel do professor passa ser de amparar os alunos, não mais de transmitir informações.

Dessa forma, as metodologias de ensino devem ser dinâmicas, não apenas com o objetivo de os estudantes desenvolverem competências técnicas, mas também para desenvolverem habilidades interpessoais e espírito crítico. Nesse contexto, a metodologia de problematização tem como diferencial o uso de uma situação-problema, buscado pelos próprios alunos de uma equipe, para o estímulo pela busca de conceitos fundamentais e uso de suas habilidades para solução (BOROCHOVICIUS; BARBOSA TORTELLA, 2014).

Já que a forma de se aprender mudou, faz-se necessário mudar a forma de ensinar, e é nesse contexto que o presente estudo se justifica. Assim, o objetivo geral deste estudo consistiu em avaliar a influência das metodologias ativas de aprendizagem, sala de aula invertida e a problematização, no ensino do conteúdo de óptica, parte integrante da disciplina de Física II da grade curricular do curso de graduação em Engenharia Civil do UniFOA, com base em testes e autoavaliação dos estudantes.

\section{METODOLOGIA}

O presente estudo de caso constituiu uma ação educacional realizada no período letivo de 2017.1, utilizada como estratégia para o ensino da disciplina de Física Il e, em decorrência, o aprimoramento do aprendizado dos estudantes. 0 conteúdo de óptica, componente da referida unidade curricular do curso de Engenharia Civil do UniFOA, foi selecionado para aplicação da metodologia de ensino denominada sala de aula invertida (SAI) e problematização. Na ocasião, 32 alunos aceitaram participar da atividade.

Inicialmente, foi proposta aos estudantes a realização de um teste, aqui chamado de pré-teste, elaborado em níveis de complexidade crescentes inspirado na Taxonomia de Bloom, que consistiu em dez questões fundamentais de múltipla escolha assim distribuídas: 3 questões de conhecimento, 3 questões de compreensão e 4 questões de aplicação. Após esse momento, foi proposto um estudo individual por meio de um material didático desenvolvido pela própria Professora da disciplina disponibilizado on-line na área restrita virtual dos estudantes. Esse material consistiu em textos compactos, ilustrados com imagens e com links de vídeos disponíveis na Internet. Foi estabelecido um prazo de duas semanas para realização dessa etapa do ciclo de atividades. 
Decorridas as duas semanas, um novo teste individual foi aplicado. Esse pós-teste consistiu em 15 questões, ou seja, as mesmas dez questões de múltipla do pré-teste e mais 5 questões discursivas (2 de análise e 3 de síntese). Após a realização do pós-teste, os estudantes foram distribuídos em 8 grupos de trabalho (GT) para discussão e avaliação das respostas individuais, na tentativa de se alcançar um consenso do GT para a construção de um gabarito único por GT.

Finalizados os gabaritos únicos, os $8 \mathrm{GTs}$ foram reunidos em uma mesa redonda e os gabaritos foram rediscutidos, sob a mediação da Professora, que, então, propôs uma nova etapa da atividade: a elaboração de um vídeo de 20 minutos sobre assuntos relacionados às importâncias e aplicações da óptica na engenharia para resolução de problemas. Os temas foram de livre escolha.

Uma avaliação sobre expectativa e satisfação dos estudantes com o novo método de ensino-aprendizagem também foi realizada por meio de um único questionário anônimo aplicado antes e depois da realização da atividade para percepção da aquisição de novas competências. O referido questionário consistia em quatro questões, cujas respostas possíveis eram apenas sim ou não, a saber: Você conhece alguma metodologia ativa de ensino-aprendizagem? Você se considera autônomo no processo de aprendizagem? Você se sente motivado com experiências como essa? Você acha que atividades como essa ampliam a aprendizagem?

Todos os dados coletados foram tabulados e analisados.

\section{$3 \quad$ RESULTADOS E DISCUSSÕES}

Os resultados dos testes, pré e pós-estudo individualizado, para as 10 questões de múltipla escolha são apresentados na Figura 1, na qual é possível observar considerável evolução na aquisição de habilidades pós-estudo individualizado.

Figura 1 - Resultados dos testes pré e pós-estudo individualizado para as 10 questões de múltipla escolha.

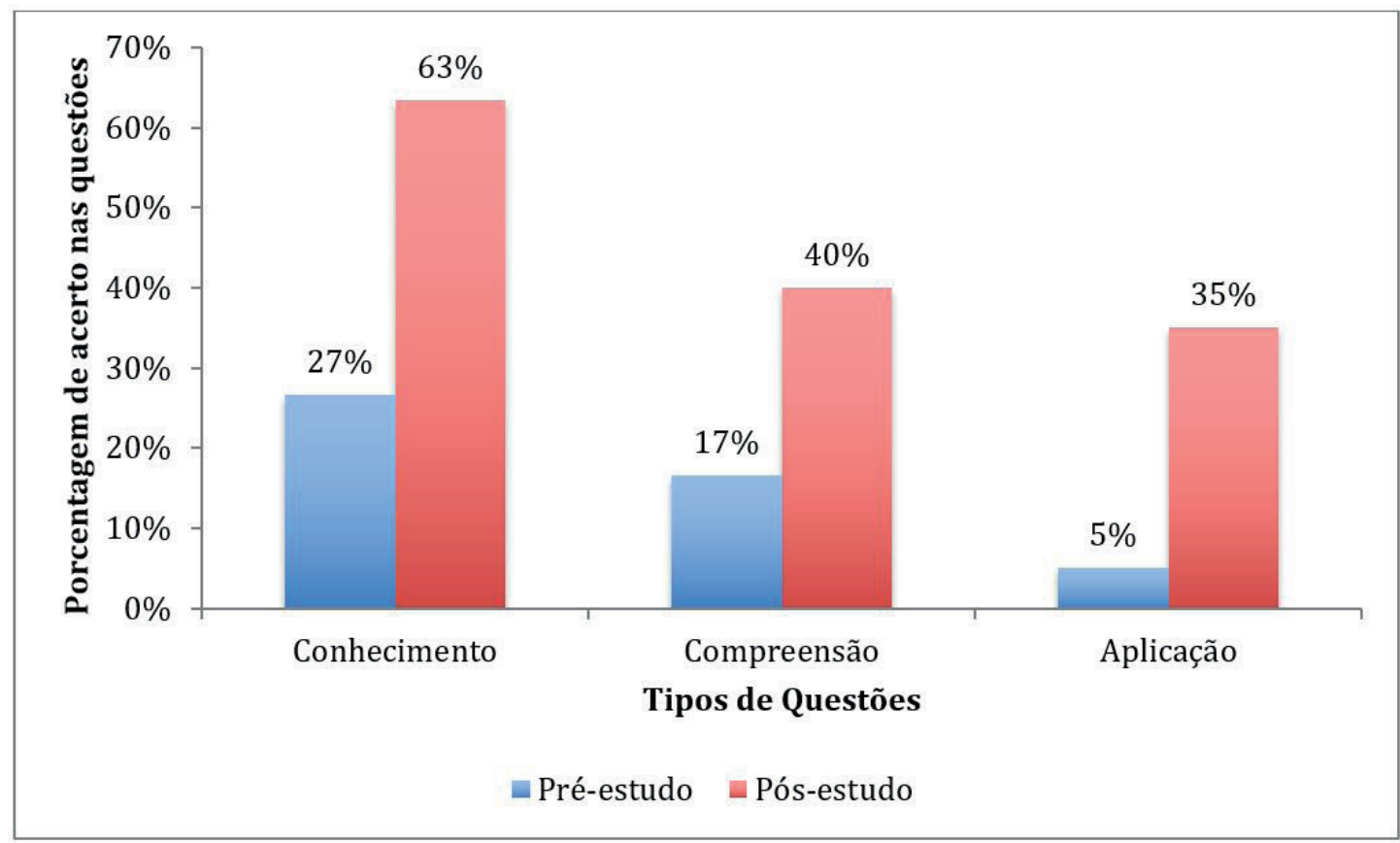

Fonte: autora, 2019. 
A sala de aula invertida e a problematização aplicadas ao ensino da física II: um estudo de caso no curso de graduação em engenharia civil do UniFOA no período letivo de 2017.1

As atividades de aprendizagem individualizada fora da sala de aula e as interativas em equipe em sala de aula dinamizaram a aprendizagem, conforme pode ser observado na Figura 2. De acordo com Bishop e Verleger (2013), a SAl, além de oportunizar a independência dos aprendizes na sua própria construção do conhecimento, possibilita o melhor aproveitamento do tempo em sala de aula, como também estimula a participação dos alunos nas atividades.

Segundo Bergamann \& Sams (2016), os conteúdos, quando disponibilizados on-line, permitem que os estudantes não somente organizem seu próprio ritmo de estudo, mas também identifiquem previamente as questões que necessitam de um maior aprofundamento para serem mais bem assimiladas, o que torna o aprendizado mais dinâmico e flexível.

Figura 2 - Resultados dos testes pós estudo e dos gabaritos dos GTs.

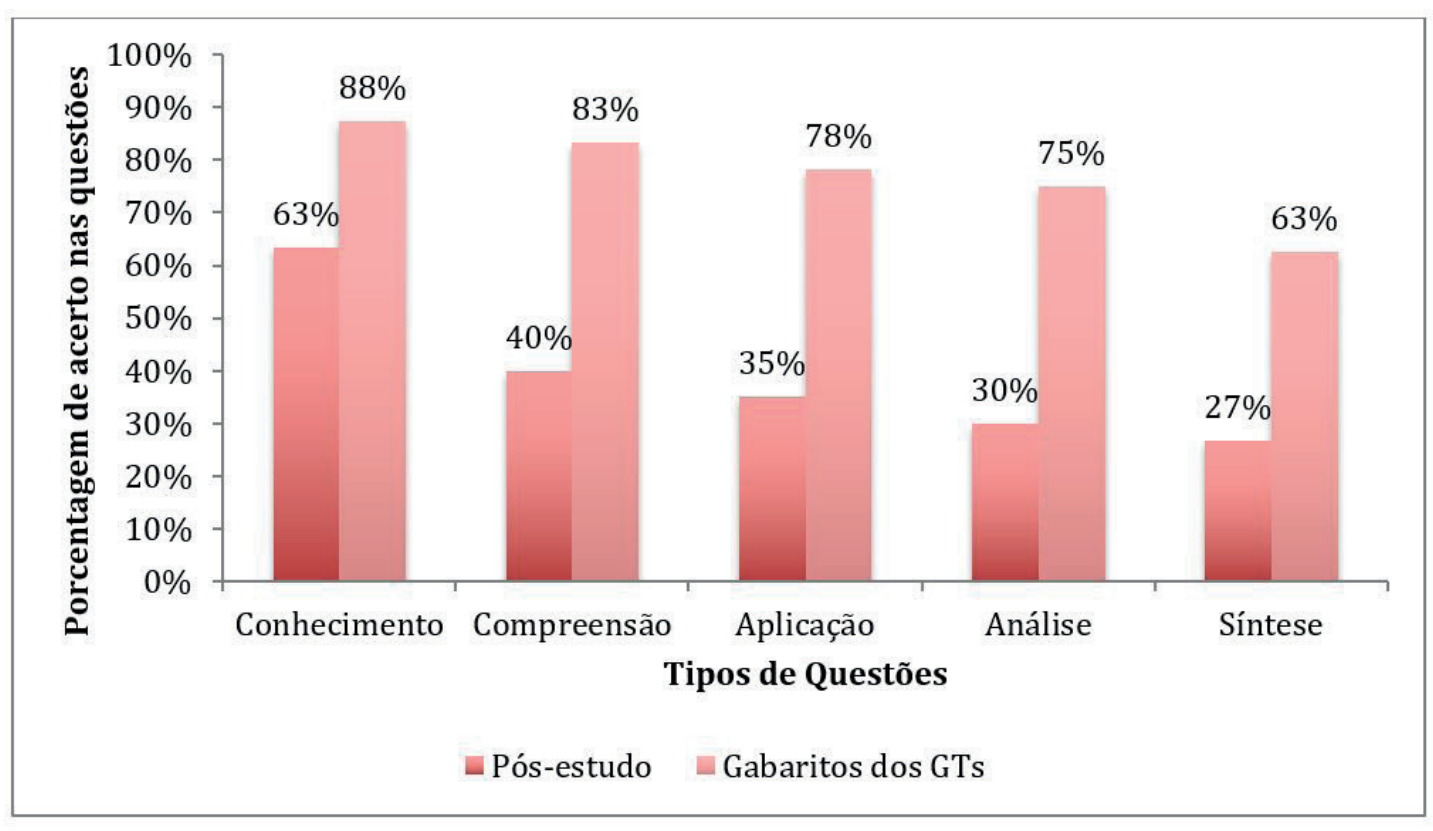

Fonte: autora, 2019.

Após a professora certificar-se de que os estudantes alcançaram ganhos significativos de compreensão conceitual, posteriormente à etapa de SAl, foi proposto aos $8 \mathrm{GTs}$ a busca de uma situação-problema relacionada às importâncias e aplicações da óptica na engenharia para elaboração de um vídeo de 20 minutos. A Tabela 1 apresenta os temas escolhidos por cada GT.

Tabela 1 - Temas dos vídeos produzidos por cada GT.

\begin{tabular}{cl}
\hline Tema & Número de alunos em cada GT \\
\hline O uso do laser na Engenharia & 4 \\
\hline O Telescópio & 4 \\
\hline O uso de vidros espelhados nas construções & 4 \\
\hline Os sensores de presença e movimento & 4 \\
\hline Os painéis solares & 4 \\
\hline A microscopia & 4 \\
\hline A fibra óptica & 4 \\
\hline
\end{tabular}

Fonte: autora, 2019. 
Todos os vídeos foram assistidos pela turma e um novo ciclo de debates foi estabelecido. Todos os GTs declararam publicamente que a atividade de educomunicação "deu muito trabalho", mas que ampliou seu potencial inventivo e de planejamento.

De acordo com Reis (2005), uma das maiores reclamações dos alunos dos cursos de engenharia é o ensino da teoria sem relação com a prática e a realidade profissional. Assim, o uso da problematização como ferramenta de "ensinagem" de parte do conteúdo teórico da Física II se traduziu em uma boa alternativa de aprendizagem dessa disciplina básica do curso de graduação em engenharia civil.

Os resultados do questionário de autoavaliação sobre a expectativa e satisfação para a vivência da sala de aula invertida e problematização são apresentados na Tabela 2, por meio da qual fica evidente que, no início da proposta, boa parte dos estudantes não conheciam metodologias ativas de ensino e aprendizagem, bem como acreditavam que as aulas teóricas ministradas presencialmente pela professora constituíam a melhor forma de aprendizagem de Física II. Porém, ao final da atividade, foi notório que ferramentas como essas acarretam numa mudança de comportamento do estudante, que passa a ser o protagonista da sua própria aprendizagem, percebendo considerável autonomia no processo.

Tabela 2 - Resultados do questionário de expectativa e satisfação.

\begin{tabular}{lcc}
\hline \multirow{2}{*}{ Questões do questionário de expectativa e satisfação } & \multicolumn{2}{l}{ Porcentagem de respostas positivas (sim) } \\
\cline { 2 - 3 } & Antes & Depois \\
\hline $\begin{array}{l}\text { Você conhece alguma metodologia ativa de ensino- } \\
\text { aprendizagem? }\end{array}$ & $28 \%$ & $100 \%$ \\
\hline Você se considera autônomo no processo de aprendizagem? & $34 \%$ & $78 \%$ \\
\hline Você se sente motivado com experiências como essa? & $13 \%$ & $81 \%$ \\
\hline Você acha que atividades como essa ampliam a aprendizagem? & $13 \%$ & $84 \%$ \\
\hline
\end{tabular}

Fonte: autora, 2019.

Outro aspecto relevante evidenciado na Tabela 2 é o expressivo aumento da motivação dos estudantes com experiências como essas, que confirmam que a estratégia de ensino superou as expectativas da maioria dos alunos que participaram do ciclo de atividades.

Pavanelo e Lima (2017), ao utilizarem a ferramenta da sala de aula invertida no ensino de Cálculo I, também perceberam anseio dos alunos por mudanças relacionadas ao processo de ensino e de aprendizagem, bem como a motivação deles após o uso da metodologia.

\section{CONCLUSÕES}

Os resultados do presente estudo de caso comprovaram que as metodologias ativas de ensino utilizadas se apresentaram como uma eficiente alternativa para o ensino do conteúdo de ótica, já que houve aprendizado significativo pelos estudantes.

Além disso, essas metodologias apresentaram, como principais diferenciais no processo de aprendizagem, o aumento da autonomia dos estudantes e a avaliação do conhecimento adquirido na etapa de problematização, que exigiu dos alunos a habilidade em fazer julgamentos levando em consideração critérios já conhecidos em diferentes níveis de complexidade. 
A sala de aula invertida e a problematização aplicadas ao ensino da física II: um estudo de caso no curso de graduação em engenharia civil do UniFOA no período letivo de 2017.1

\section{REFERÊNCIAS}

ARAÚJO, U. F. A quarta revolução educacional: a mudança de tempos, espaços e relações na escola a partir do uso de tecnologias e da inclusão social. ETD - Educação Temática Digital, Campinas, v. 12, n. esp., p. 3148, mar. 2011.

BISHOP, J. L.; VERLEGER, M. A. The Flipped Classroom: A Survey of the Research. In: ASEE Annual Conference \& Exposition, 120, Atlanta. Anais. Washington DC, American Society for Engineering Education, 2013.

BERGMANN, J.; SAMS A. Sala de aula invertida: uma metodologia ativa de aprendizagem. Trad. Afonso Celso da Cunha Serra. 1. ed. Rio de Janeiro: LTC, 2016.

BOROCHOVICIUS, E.; BARBOZA TORTELLA, J. C. Aprendizagem Baseada em Problemas: um método de ensinoaprendizagem e suas práticas educativas. Ensaio: Avaliação e Políticas Públicas em Educação, v. 22, n. 83, 2014.

CUNHA, M. I. Docência na universidade, cultura e avaliação institucional: saberes silenciados em questão. Revista Brasileira de Educação, Rio de Janeiro, v. 11, n. 32, p. 258-271, maio-ago. 2006.

HENGEMÜHLE, A. Formação de professores: da função de ensinar ao resgate da educação. 2. ed. Rio de Janeiro: Vozes, 2008.

PAVANELO, E.; LIMA, R. Sala de Aula Invertida: a análise de uma experiência na disciplina de Cálculo I. Bolema, Rio Claro, v. 31, n. 58, p. 739-759, 2017.

SCHMITZ, E. X; REIS, S. C. Sala de aula invertida: investigação sobre o grau de familiaridade conceitual teóricoprático dos docentes da universidade. Revista ETD: Educação Temática Digital, v. 20, p. 153-175, 2018.

REIS, F. A. G. V. Aplicação da metodologia da problematização em disciplinas de Engenharia Ambiental. Tese de Doutorado (Geociências e Meio Ambiente). Universidade Estadual Paulista Júlio De Mesquita Filho/Rio Claro, 2005.

VALENTE, J. A. Blended learning e as mudanças no ensino superior: a proposta da sala de aula invertida. Educar em Revista, Curitiba, n. 4, p. 79-97, 2014. 